\title{
Research on the Development of Agricultural Logistics Based on Internet of Things (IOT)
}

\author{
Wang Xiaobin \\ School of Economic and Management \\ Shenyang Aerospace University \\ Shenyang, China
}

\author{
Peng Yingtao \\ School of Economic and Management \\ Shenyang Aerospace University \\ Shenyang, China
}

\begin{abstract}
For the past few years, the study on the technology of internet of things (IOT) has become a hot topic of the field of science at home and abroad. In the filed of farm products logistics, the technology of internet of things can effectively track, trace and manage the farm products in the supply chain of logistics; suppliers can acquire the real-time sales status of farm products so as to adjust production and supply of farm products in time; consumers can query the production process and detailed information in order to ensure the quality of farm products. Via the technology of internet of things, we can not only trace each link of supply chain of farm products and share information, but also analyze the current situation of farm products; we can predict the probability of accident, take measures in a timely and effective manner, and enhance the ability of response mechanism to the market regulation.
\end{abstract}

Keywords- Internet of Things (IOT); farm products; logistics; architecture; study

\section{INTRODUCTION}

At present, the high cost of logistics is the main factor which restricts the development of the farm products logistics. Establishing the platform of farm products logistics information network, perfecting information service system, and how to make the whole logistics process more transparent and effective are the direction for the development of farm products logistics in the future. However, the generation of the IOT has brought vigor and vitality for the farm products that are at the choke point stage. The surveillance of IOT to the logistics process can improve efficiency and greatly reduce logistics costs. The application of the IOT technology can effectively improve the response speed of logistics supply chain of farm products, and reduce the time cost and opportunity cost of farm products logistics.

The IOT improves the development of farm products logistics, and effectively reduce the cost of logistics. The development of information technology is so fast today that RFID technology, sensors, and electronic label for farm products have been applied in the farm products logistics; the transportation of farm products, storage, planting and reverse logistics have come true under the Internet of things.

\section{STATUS QUO AND PROBLEMS OF FARM PRODUCTS LOGISTICS IN CHINA}

\section{A. Status quo of farm products logistics in China}

The system of farm products logistics is gradually improved, but the regional development is unbalanced; the sound momentum is the diversification of main body and trading manner of farm products; the gradually formed situation is traditional circulation channels as the domination and new circulation form.

At present, the processing rate of agricultural products in developed countries reaches more than $80 \%$, while the rate is only $45 \%$ in China. The reasons for the situation is most of the links are done by farmers themselves in the whole process of farm products logistics; low intensification and scale, simple and crude devices for circulation and processing, no application of the equipments for special filter, washing, waxing and package of farm products in reality; the degree of mechanization of production is far below than developed countries, which makes the comprehensive utilization of agricultural resources low.

The regional segmentation is severe and the scale of enterprises is small. For a long time, due to the influence of planned economy, the logistics pattern in China is diversified. Most of the third-party logistics enterprises are transformed from the sectors of commerce, supplies, food and transportation in the period of planned economy apart from emerging foreign-owned and private enterprises. The regional segmentation is severe; enterprises are lack of integration; the intensive management advantage is not obvious; scale benefits are hard to achieve.

Customer satisfaction is low. Most of the logistics enterprises can only provide single or segmented logistics services. Logistics functions mainly stay on the storage, transportation and urban distribution; there are few related value-added services such as packaging, processing and distribution, which cannot form complete logistics supply chain. According to the survey of China warehousing association in early 2001, of the enterprises adopting third-party logistics, $23 \%$ of the production enterprises and $7 \%$ of the commercial enterprises are not satisfied with third-party logistics services.

Outdated logistics concepts and phenomenon of selfmanagement is outstanding. Due to the wrong understanding of logistics as "the third profit source" and the idea of "large and all-inclusive" and "small and all-inclusive", lots of production or business enterprises 
are afraid of losing the control of procurement and sales, and afraid of the loss of profits earned by other enterprises; the enterprises establish their own logistics system and are reluctant to seek outward logistics services. According to the survey of 2000 enterprises by China Storage Association in 2001, the third-party logistics business accounted for only $21 \%$ and $13 \%$ in production and business enterprises separately.

Cost and accounts are unclear, and logistics channels are poor. Most of the tax offices haven't defined how to share costs and keep accounts. The logistics industry is a highly integrated industry, receiving almost all kinds of invoices in society, even blank note. Due to no invoice, expenditure can't be entered into the account book, so people are forced to buy the invoice.

Logistics talent reserve is not enough, and facilities are outdated. The logistics industry is still in its infancy in our country; higher education and vocational education can't keep up with the development due to the lack of talent and poor quality; the current logistics infrastructure is simple and outdated, which is difficult to adapt to the needs of the development of modern logistics. Generally, logistics infrastructure investment is big but slow effect; the logistics industry has great social benefits, but low profit margins; it's difficult to take effect only by enterprise investment.

\section{B. Existing problems of farm products logistics in China}

\section{1) Excessive input cost of farm products logistics}

Most of the agricultural production mode in China is small-scale by farmers, and lack of large-scale base production. Due to scattered planting, farmers are blind in choosing crop varieties and lack of market demand information, so there is a certain gap between the supply and market demand. Due to the dispersion of the procurement of capital goods, the cost of input is too high, availability of capital goods is low, and farming logistics is easily affected by the logistics environment.

\section{2) Poor logistics technology}

China's rural logistics infrastructure and equipment are outdated, and technical conditions cannot meet the demand of market. Meanwhile, the characteristics of freshness and perishability make higher requirements for agricultural products logistics. Limited to the comparatively low level of the development of logistics technology and low mechanization level of product processing and packaging, it's impossible to meet the needs of transportation, processing, packaging and information processing for farm products. In storage link, the attrition rate of farm products is relatively high when stored in the hands of farmers due to lack of sound warehousing conditions.

\section{3) Incomplete logistics system}

The means of transportation is incomplete in rural regions; the information transfer lags far behind the development of logistics industry demand; effective information guidance is scarce; the variety and quality provided by the agricultural information system and agricultural logistics information system cannot meet the need; the supports of technology and money are not enough to establish and improve the logistics system.

\section{A. Overview of Internet of Things}

Compared with traditional internet, IOT possesses distinctive features.

First of all, it is an extensive application of all sorts of sensing technology. IOT deploys a large number of different sensors, each of which is a source of information, and different types of sensors capture different information content and format. The data obtained by the sensors are real-time; the sensors collect and update constantly according to certain frequency period.

Second, it is a network based on Internet. The important foundation and core of IOT is still the internet, merging together with the internet through all kinds of wired and wireless networks, and delivering real-time information of objects. The information obtained from sensors regularly of IOT will be transmitted through networks, and forms huge amounts of information. In the process of transmission, IOT must adapt to a variety of heterogeneous networks and protocols in order to ensure the accuracy and the timeliness of data.

\section{B. Application of IOT in farm products logistics}

\section{1) IOT for farming}

The IOT is recognized as the third wave of information industry following computer, Internet and mobile communication network of the world. On the premise of perception, it realizes the fully connected network of people to people, people to objects, and objects to objects. Underneath this, implanting all kinds of microchips in the objects, acquiring all kinds of information for the physical world by these sensors, we can finally realize the perception of the world through interaction of local wireless networks, Internet, mobile communication network.

Agricultural IOT, that is, in the greenhouse control system, the application of temperature sensor, humidity sensor, $\mathrm{PH}$ sensor, light sensor, $\mathrm{CO} 2$ sensor of IOS system, detect the physical parameters of temperature, relative humidity, $\mathrm{PH}$ value, light intensity, soil nutrient, and $\mathrm{CO} 2$ concentration in the environment. It ensures the growth of crops with good and suitable environment through real-time display of a variety of instruments or being involved in the automatic control as the parameter.

Agricultural IOT combines the Internet of things technology, sensor network technology and Internet technology together, and exists in each process from production to consumers through sensor technology, electronic product code and radio frequency technology. Through the introduction of sensor nodes in the logistics goods, it can accurately understand and grasp in each link of the supply chain from procurement, production, manufacturing, packing/loading and unloading, storage, transportation, distribution/sales distribution, sales to service.

\section{2) Production of farm products}

Intelligent agriculture is the trend of the future agricultural development. Application of sensor technology of IOT into agricultural production can timely grasp the demand of growth environment for 
crops, control the environment scientifically, and obtain high-yield and high-quality agricultural products; sensor technology can be used to accurately confirm the crop information, timely monitor the soil moisture information for crop growth, for example, the indoor temperature and humidity monitoring of greenhouses operation, and automation management in the field are all the typical application of IOT in agricultural production.

3) Storage and transportation of farm products

Goods receiving: Application of Internet of things technology can effectively track the transport of goods. Labeling the Electronic Product Code (EPC) on the vehicles and goods for transportation can grasp the location of the goods, track the vehicles, and timely grasp the information of goods; people gradually increase requirements for basic necessities of life, consumers expect to buy fresh agricultural and sideline products coupled with strict limits for the storage environment, so suppliers must be in accordance with the best storage conditions of the goods and deliver the purchased agricultural products to the destination in time.
Inventory check: Due to the particularity of agricultural products, storage time of general fresh agricultural products is shorter, so we need high efficient inventory management. Check is to verify the consistency of entity and the logical record. The application of RFID in entity check can reduce labor intensity and improve the efficiency and accuracy of inventory check. When sorting inventory goods, you only need to scan EPC labels on the goods to accurately know the products including warehousing date, origin, production date, expiration date, etc. After finishing the inventory information summary, timely report to the administrative department so as to achieve the overall understanding of the inventory goods information and help distributors improve the management efficiency of warehouse and reduce product loss rate.

Sales of agricultural products: Taking advantage of radio frequency technology in sales of fresh agricultural products and reading automatically various information of the product through the embedded electronic tag, which help monitor the listing and inventory number of goods so as to replenish and deal with the expired products timely.
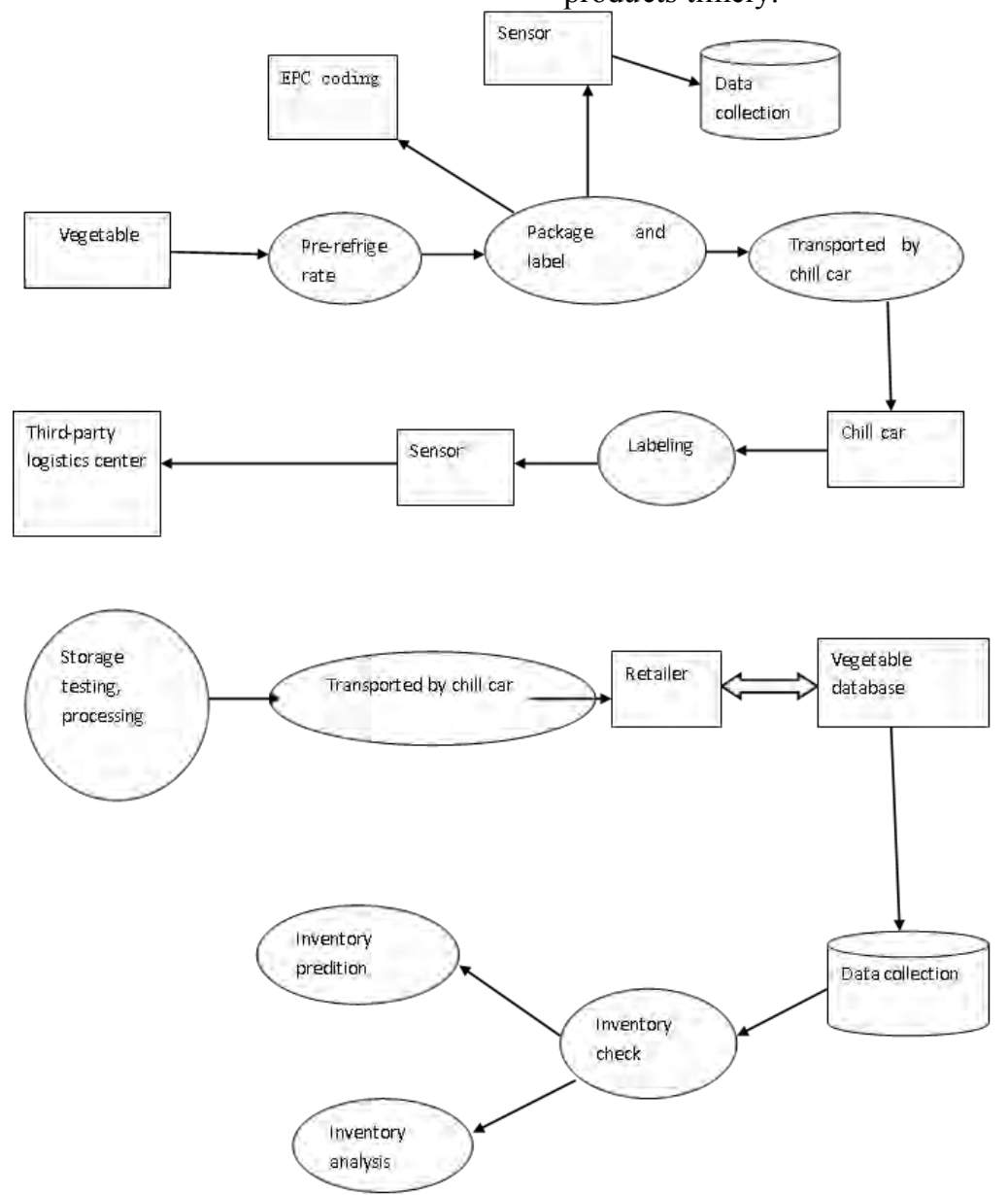

Figure 1. Planning chart of logistics system of vegetable cold chain based on RFID technique 
IV. SUGGESTION TO THE DEVELOPMENT OF FARM PRODUCTS LOGISTICS BASED ON IOT

\section{A. Development trend of farm products logistics based on IOT}

Application of IOT technique in the agricultural products logistics is still in its infancy; the direction of the development priority is to have the features of microminiature, reliability, energy-saving, environmental adaptability, low cost, intelligence. With the popularity of computer in the countryside, the Internet can be used to popularize knowledge of agricultural science, strengthen farmers' cognitive level of IOT, and accelerate the popularization of IOT in the countryside.

Making use of the advanced IOT technique in farm industry for farm products network management, such as effective products processing, transportation, storage, information processing, the integrated treatment to the information of the farmer, merchants and consumers for the construction of the complete farm products supply chain can improve the information-based level of agricultural product supply, complete the logistics supply channel, reduce logistics cost, and enhance the development of logistics supply for farm products in China.

It plays an irreplaceable role for the quality supervision and quality improvement of farm products to apply the IOT technique into the food security assurance and food traceability of farm products. Query the records all relevant data in the process of agricultural production through the EPC code of the items so as to trace back the farm products and supervise the quality as well as track the farm products in the process of transportation and reduce the loss during the transportation.

Label EPC on the farm products, enter the unique ID code on behalf of the farm products and various formal and interoperable information, collect these information into the central information system through the communication network of wireless data, so as to recognize the farm products, exchange and share through open computer network and realize the quality safety management of farm products.

At every stage of farm products choosing for plant to flowing into the market, the IOT technique can be applied for improving efficiency in order to achieve high quality, high production and efficiency of farm industry, strengthening information exchange between farmers and market through intelligent information management and information network, which help farmers know the market changes, select products suitable for the market demand, reduce the risk of blind planting and strengthen the product safety consciousness; plant crops that are suitable for the local development according to the environment of producing area.

\section{B. Suggestions to the development of farm products logistics based on IOT}

1) Actively play the role of the government's macrocontrol. The government plays an irreplaceable role in the process of farm products logistics development, especially in making the macro guidance plans, the collection and distribution of agricultural products logistics information, laying out the logistics market rules, providing favorable policies for land, capital, tax and so on. The government actively plays the role of macro-control, which is fundamentally promoting the agricultural IOT.

2) Introducing advanced agricultural logistics technology and management methods. Actively increase the technical input to the logistics of agricultural products, increase the intensity of logistics technology development, constantly improve the level of agricultural products logistics technology, reduce the loss in the process of the logistics of agricultural products and agricultural products logistics cost so as to increase the profit of agricultural products in logistics link. Actively introducing advanced logistics technology and management methods, can fundamentally solve the existing problems in the logistics of agricultural products, effectively reduce logistics cost, solve the problem of backward technology and incomplete logistics system.

3) Cultivating and improving logistics main body of farm products

4) To establish high-level farm products logistics center so as to achieve the integration and ordering of farm products logistics.

5) To strengthen the education and training of agricultural logistics. Construct education system for modern agricultural logistics talents; cultivate adaptive high-quality talents for the needs of modern agricultural development. Actively deliver the knowledge of IOT for farm products and train, so the farmers know more about agricultural IOT technique and benefit from the practice..

\section{CONCLUSION}

Farming IOT technology is the need for future farming development; the application of IOT in farming production will greatly improve the level of agricultural information and ensure the quality and safety of agricultural products, which plays an important role in changing the comparatively unsophisticated status of farm products logistics and promoting the development of modern agriculture in our country. Through the combination of modern agricultural logistics and IOT technology, promoting the industrialized development of agricultural logistics, improving the existing problems of rural logistics and speeding up the development of agriculture logistics is of obvious improvement to the output and quality of farm products. However, the application of the technology of IOT in rural products logistics is still in its infancy, and further research is needed due to the development level of IOT.

\section{REFERENCES}

[1] He Yan. Smart sales system of farm products under the Internet of Things [J]. Heilongjiang Science, 2012, 3(1): 57-59.

[2] Xu Keying. Agricultural information- the development trend of agricultural modernization in $21 \mathrm{st}$ century[J]. Agricultural modernization research institute, 1999, 20(4): 215-217.

[3] Ning Huansheng, Xu Qunyu. Some thoughts of global IOT development and China IOT construction[J]. E-journal, 2010, 38(11): 2590-2599.

[4] Pi Shaohui, Yang Jingshuai, Wang Juan,etc. Discussion on the application of IOT technology in farm products logistics [J]. Logistics technology, 2011, 34(9): 3-5. 
[5] Qiao Jinliang. How to better combine the IOT with farming[J]. Marketing industry: agricultural capital and market, 2013 (24): 64-65.

[6] Si Kai, Zang Liang. Study on the application of IOT in farming industry[J]. Rural economy and technology, 2011, 22(8): 41-43.

[7] Yang Zhanpeng. Analysis on the status quo and suggestion to the development of IOT in China [J]. Market modernization, 2011 (14): 11-12.

[8] Yan Bo, Xiang Wei, Ran Zesong, etc. Information sharing of farm products IOT supply chain based on RFID [J].Science and technology Management Research, 2012, 32(7): 109-112.

[9] Ma Yiding. Prospects of IOT through application [J]. Ebusiness condition of China: Basic electronics, 2010 (1): 49-50.
[10] Yang Xiaoyong, Bai Xiaohui, Jiang Han. SWOT analysis and countermeasure suggestion to the development status of IOT in China [J]. Market forum, 2012 (11): 70-73

[11] Li Hongyan, Gui Chao. Application and development trend of IOT[J]. Fujian computer, 2010 (009): 1-2.

[12] Maarten Botterman.Internet of Things:an early reality of theFuture Internet. . 2009

[13] Harald Sundmaeker,Patrick Guillemin,et al.Vision and Challenges for Realising the Internet of Things. . 2010

[14] Commission of the European Communities. Internet of ThingsAn action plan for Europe. COM(2009)278final . 2009 